\title{
Effects of adding methacrylate monomers on viscosity and mechanical properties of experimental light-curing soft lining materials based on urethane (meth)acrylate oligomers.
}

\author{
Takahito KANIE ${ }^{1}$, Akihiko KADOKAWA², Hiroyuki ARIKAWA ${ }^{1}$, Koichi FUJII ${ }^{1}$ and Seiji BAN ${ }^{1}$ \\ ${ }^{1}$ Department of Biomaterials Science, Graduate School of Medical and Dental Sciences, Kagoshima University, 8-35-1 Sakuragaoka, Kagoshima \\ 890-8544, Japan \\ ${ }^{2}$ Department of Fixed Prosthetic Dentistry, Graduate School of Medical and Dental Sciences, Kagoshima University, 8-35-1 Sakuragaoka, \\ Kagoshima 890-8544, Japan \\ Corresponding author, Takahito Kanie; E-mail: einak@ms.kagoshima-u.ac.jp
}

\begin{abstract}
We investigated the viscosity and mechanical properties of experimental light-curing soft lining materials based on six commercially available urethane (meth)acrylate oligomers. The viscosities of the six oligomers were 1.9, 20.6, 26.8, 144.0, 185.3 , and $8803.4 \mathrm{~Pa} \cdot \mathrm{s}$ at $25^{\circ} \mathrm{C}$. Two monomers (ethyl- and butyl-methacrylate) were added at 20 wt\% to these oligomers to decrease the viscosity, resulting in viscosity reductions of 0.2 to $13.6 \mathrm{~Pa} \cdot \mathrm{s}$ for the six oligomers. The mechanical properties (compressive modulus, Shore A hardness, and tensile strength) were measured after two times light-polymerization for 3 min. The addition of the monomers to the oligomers only slightly changed the mechanical properties, in contrast to the large viscosity changes. Based on these results, it appears that the addition of ethyl- or butyl-methacrylate monomers is useful for decreasing the viscosity of experimental light-curing soft lining materials without changing their mechanical properties.
\end{abstract}

Key words: Soft lining material, Mechanical property, Urethane oligomer.

Received Jun 10, 2008: Accepted Jul 28, 2008

\section{INTRODUCTION}

Recently, two types soft lining materials, acrylic and silicone rubber materials, have been used in dentistry ${ }^{1)}$. Acrylic lining materials bond to acrylic denture base resins but tend to harden because of the loss of plasticizer in the mouth and roughening of the surface by denture cleansers ${ }^{2,3}$. Silicone rubber materials do not adhere well to acrylic denture base resins; thus, primers and finishing materials are used to induce adherence to acrylic denture base resins ${ }^{4,5)}$. However, the durability of these materials is typically only a few months. In clinical use, the two lining materials are applied to denture base resins after the denture has been made; that is, these lining materials are added to dentures in use.

In a new type of denture, soft material (Physio Soft Rebase, Nissin, Kyoto, Japan) is composed of acrylate monomers and is prepared by mixing powder with liquid. Before filling dough of the soft material, space was made by spacer between dough of the denture base resin and the model plaster and then dough of the soft material is placed in the tissue side space on the model plaster. Two doughs, the soft material and the denture base resin, were concurrently polymerized by heating. Regulating the hardness and thickness of this product is difficult.

Our previous investigation ${ }^{6)}$ suggested that a strong bond between methylmethacrylate and urethane polymers, made from urethane (meth) acrylate oligomers, occurred when an unpolymerized chemical-curing methylmethacrylate mixture was poured onto urethane polymers and then cured. Using this procedure and urethane oligomers, new soft lining material can be made with the soft materials on the tissue side; the mechanical properties of these materials have been studied ${ }^{7}$. "Urethane oligomer" is a generic name for a polymer with comparatively low molecular weight $(1,000$ $10,000)$ in which the urethane bond is synthesized from polyols and di-isocyanates. In such materials, urethane acrylate oligomers with terminal groups available for a radical reaction can display a wide range of viscosities, depending on the molecular weight and specific terminal group(s). Cured urethane polymers also show a wide range of properties, from soft to hard. Furthermore, urethane acrylate oligomers can be cured by benzoyl peroxide and camphorquinone, in much the same way as the dental technique. The new soft lining material is put on the model plaster and trimmed by the dentist or dental technician. At this stage, viscosity is an important factor, because soft lining materials must flow readily during morphological preparation. In the present study, experimental light-curing soft lining materials (ESLM) of urethane (meth)acrylate 
oligomers with or without methacrylate monomers were prepared and then the viscosity of the ESLM before polymerization and the mechanical properties of the ESLM after polymerization were assessed.

\section{MATERIALS AND METHODS}

\section{Materials}

Six soft-type urethane (meth)acrylate oligomers and two methacrylate monomers were used as components of ESLMs (Table 1). The materials examined consisted of the urethane oligomers ( $0 \mathrm{wt} \%$ methacrylate monomer) and the urethane oligomers with the addition of $20 \mathrm{wt} \%$ ethylmethacrylate (EMA) or 20 wt\% $n$-butylmethacrylate (BMA) monomers. We also added 1 wt\% camphorquinone (Wako Pure Chem., Osaka, Japan) as a photosensitizer and $1 \mathrm{wt} \%$ 2-(dimethylamino)ethylmethacrylate (Wako Pure Chem.) as a reducing agent. A homogenizing machine (AR-100, Thinky, Tokyo, Japan) with high-speed rotation and orbital motion was used to mix the materials in a dark room. The mixtures were stored in light-proof bottles for ESLM.

\section{Measuring methods}

Before photo-polymerization, the viscosities of ESLMs were measured using the cone plate at an angle of $1^{\circ}$ with $\mathrm{D}=20 \mathrm{~mm}$ on a viscometer (ReoStress 600, Haake, Karlsruhe, Germany), at a shear rate of $10 \mathrm{~s}^{-1}$ and at $25^{\circ} \mathrm{C}$.

Each ESLM was put into a polyethylene tube (11 $\mathrm{mm}$ in diameter $\times 10 \mathrm{~mm}$ in height) on a glass plate, and the top of the tube was covered with another glass plate. It was then polymerized two times for 3 min -once from the top and the other from the bottom- using a light irradiation unit ( $\boldsymbol{\alpha}$-Light, Morita, Tokyo, Japan) composed of halogen lamps. After removal from the polyethylene tube, the polymerized test specimen was soaked in water at $37^{\circ} \mathrm{C}$ for 1 day. A compression test was performed with a universal testing machine (TG-50kN, Minebea, Nagano, Japan), at a cross-head speed of $2 \mathrm{~mm} / \mathrm{min}$ in air at $37^{\circ} \mathrm{C}$, and the compressive modulus was calculated within the proportional limit. For other specimens, the Shore A hardness was measured with a durometer (GS-710, Teclock, Nagano, Japan), fixed on a constant pressure load instrument, and was loaded with a weight of about a $1 \mathrm{~kg}$, in air at $37^{\circ} \mathrm{C}$.

Each ESLM was put into a PTFE mold with a dumbbell-type hollow with $4 \mathrm{~mm}$ in width and $2 \mathrm{~mm}$ in thickness (No. 6, JIS K 6251, Japan) ${ }^{8}$, and the surface was covered with polyethylene film. The same irradiation and storage conditions as mentioned above were used for the following tests. After preparation with visible light and storage, a tensile strength test was performed with a universal testing machine, using a cross-head speed of $254 \mathrm{~mm} / \mathrm{min}$ in air at $23^{\circ} \mathrm{C}$ as referred to previous paper ${ }^{9)}$.

One-way analysis of variance and Tukey's test were used to compare the differences in apparent viscosity. Five test specimens were used for the elastic modulus, hardness, and tensile strength and the same analysis was performed.

Table 1 Six urethane (meth)acrylate oligomers and two methacrylate monomers used in this investigation

\begin{tabular}{|c|c|c|c|c|c|}
\hline Material & Manufacturer & $\begin{array}{l}\text { Functional } \\
\text { group }\end{array}$ & Type* & $\mathrm{MW}^{* *}$ & Code \\
\hline \multicolumn{6}{|l|}{ Urethane acrylate oligomer } \\
\hline $\mathrm{U}-108 \mathrm{~A}$ & Shin-Nakamura Chem. ${ }^{1}$ & 2 & Polyester & 1600 & U10 \\
\hline UA-160TM & Shin-Nakamura Chem. & 2 & Polytetramethylene glycol & 1600 & U16 \\
\hline UA-2235PE & $\begin{array}{l}\text { Shin-Nakamura Chem } \\
\text {. }\end{array}$ & 2 & $\begin{array}{l}\text { Ethylene oxide/Propylene } \\
\text { oxide }\end{array}$ & 500 & $\mathrm{U} 22$ \\
\hline UA-340P & Shin-Nakamura Chem. & 2 & Polypropylene glycol & 13000 & $\mathrm{U} 34$ \\
\hline UF-8001 & Kyoeisha Chem. $^{2}$ & 2 & Carbonate & 4500 & U80 \\
\hline \multicolumn{6}{|c|}{ Urethane methacrylate oligomer } \\
\hline SH-9832 & Negami Chem. ${ }^{3}$ & 2 & Carbonate & 1700 & S98 \\
\hline \multicolumn{6}{|l|}{ Methacrylate monomer } \\
\hline Ethyl methacrylate & Wako Pure Chem. ${ }^{4}$ & 1 & - & 114.14 & EMA \\
\hline$n$-Butyl methacrylate & Wako Pure Chem. & 1 & - & 142.2 & BMA \\
\hline
\end{tabular}

1 Wakayama, Japan ${ }^{2}$ Osaka, Japan ${ }^{3}$ Ishikawa, Japan ${ }^{4}$ Osaka, Japan

* Manufacturer's information

**Average molecular weight by manufacturer's information 


\section{RESULTS}

Figure 1 shows the variation in the viscosity of the experimental soft lining materials with or without 20 wt\% methacrylate monomers. For all ESLMs, the viscosity decreased with the addition of methacrylate monomers. In particular, the viscosity of U80 (8803.4 $\mathrm{Pa} \cdot \mathrm{s})$ decreased dramatically, to 12.1 or $13.6 \mathrm{~Pa} \cdot \mathrm{s}$ with the addition of 20 wt\% EMA or BMA, respectively.

The initial compressive moduli of the urethane oligomers were 6.6 MPa for U10, 10.6 MPa for U16,

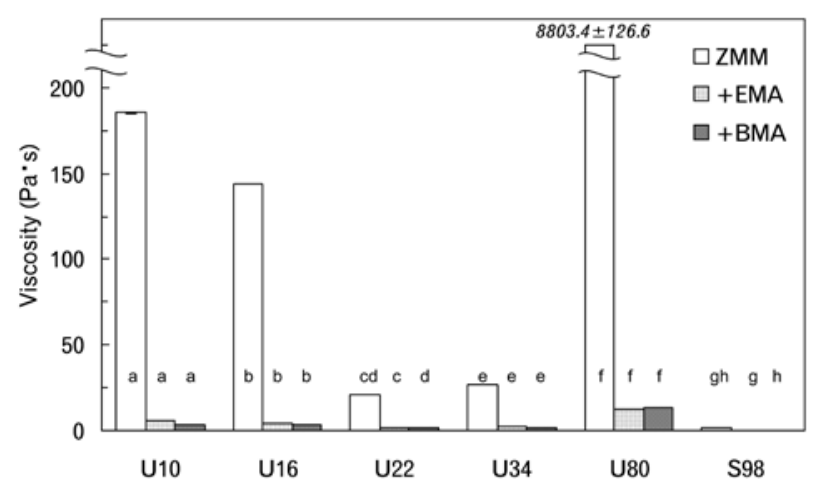

Fig. 1 The viscosity of experimental soft lining materials based on six urethane oligomers, with and without methacrylate monomers. Additions to the urethane oligomers were 0 wt\% methacrylate monomer (ZMM), 20 wt\% ethylmethacrylate (+EMA), or 20 wt\% $n$-butylmethacrylate (+BMA). Same letters over columns denote significant difference between their values of ESLMs with same letter at $\mathrm{p}<0.05$.

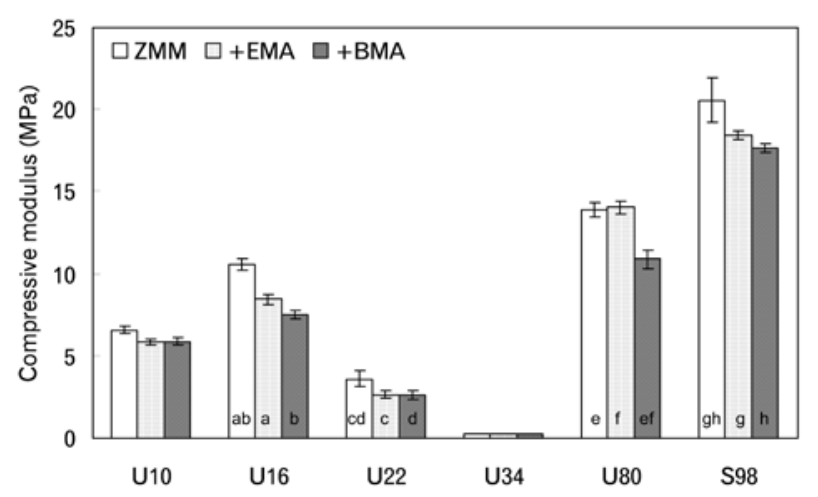

Fig. 2 The elastic moduli in compression of polymerized experimental soft lining materials based on six urethane oligomers, with and without methacrylate monomers. Additions to the urethane oligomers were 0 wt\% methacrylate monomer (ZMM), 20 wt\% ethylmethacrylate (+EMA), or $20 \mathrm{wt} \% n$ butylmethacrylate (+BMA). Same letters over columns denote significant difference between their values of ESLMs with same letter at $\mathrm{p}<0.05$.
3.6 $\mathrm{MPa}$ for $\mathrm{U} 22,0.3 \mathrm{MPa}$ for U34, $13.9 \mathrm{MPa}$ for U80, and 20.6 $\mathrm{MPa}$ for $\mathrm{S} 98$ (Fig. 2). After the addition of the methacrylate monomers, the compressive moduli of U16, U22, and S98 decreased significantly, but only the addition of BMA decreased the compressive modulus of U80 $(p<0.01)$.

As shown in Fig. 3, the initial Shore A hardness values were 57.3 for U10, 69.9 for U16, 46.9 for U22, $0.9 \mathrm{MPa}$ for U34, 87.2 for U80, and 69.3 for S98. The hardness significantly increased for U34 with the addition of the methacrylate monomers and for U10 and S98 with the addition of EMA. However, the

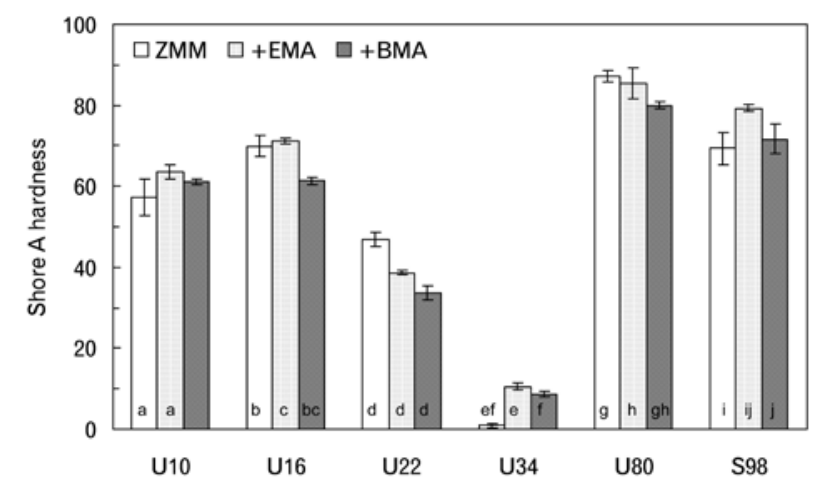

Fig. 3 The Shore A hardness of polymerized experimental soft lining materials based on six urethane oligomers, with and without methacrylate monomers. Additions to the urethane oligomers were 0 wt\% methacrylate monomer (ZMM), 20 wt\% ethylmethacrylate (+EMA), or $20 \mathrm{wt} \% n$ butylmethacrylate (+BMA). Same letters over columns denote significant difference between their values of ESLMs with same letter at $\mathrm{p}<0.05$.

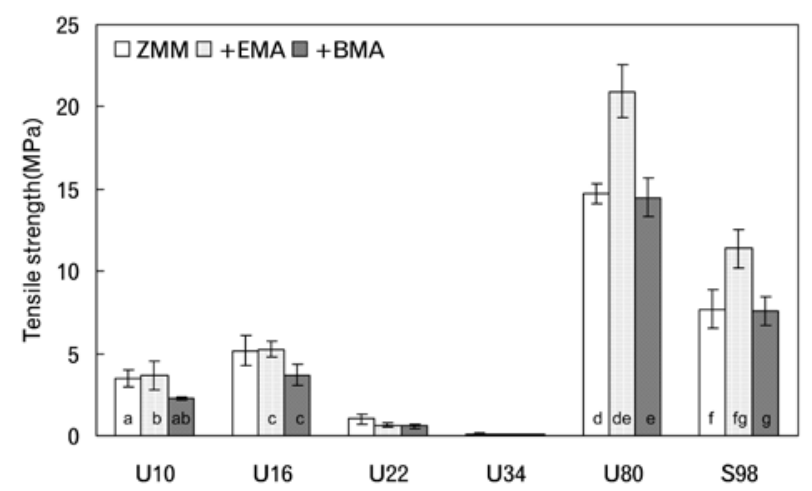

Fig. 4 The tensile strength of polymerized experimental soft lining materials based on six urethane oligomers, with and without methacrylate monomers. Additions to the urethane oligomers were 0 wt $\%$ methacrylate monomer (ZMM), 20 wt\% ethylmethacrylate (+EMA), and $20 \mathrm{wt} \% n$ butylmethacrylate (+BMA). Same letters over columns denote significant difference between their values of ESLMs with same letter at $\mathrm{p}<0.05$. 
addition of BMA to U16 and U80 and the addition of either methacrylate monomer to U22 significantly decreased the Shore A hardness $(p<0.01)$.

The initial tensile strengths were $3.5 \mathrm{MPa}$ for U10, 5.2 MPa for U16, 1.0 MPa for U22, 0.1 MPa for U34, 14.7 MPa for U80, and 7.7 MPa for S98 (Fig. 4). The tensile strengths of U80 and S98 increased significantly with the addition of EMA $(p<0.01)$.

\section{DISCUSSION}

Viscosity is an important property for the manipulability of dental materials. In particular, for our new technique ${ }^{7}$, ESLMs based on urethane oligomers are to be painted on with a brush or spatula, or put on with a thin polyethylene film on the model plaster before polymerization. For this purpose, we are planning that the viscosity should be under $100 \mathrm{~Pa} \cdot \mathrm{s}$ at $25^{\circ} \mathrm{C}$. U22, U34, and $\mathrm{S} 98$ can readily be applied with a brush or spatula, whereas other oligomers (U10, U16, and especially U80) are difficult to apply by painting. In the present investigation, we diluted the urethane oligomers with EMA or BMA monomers, which have low glass transition temperatures. Polyethylmethacrylate and polybutylmethacrylate are soft and are commonly used for soft lining materials. Our results show that with the addition of methacrylate monomers, the viscosity of the six urethane oligomers decreased; the viscosity of U80 decreased dramatically, from 8803.4 to 12.2 $\mathrm{Pa} \cdot \mathrm{s}$. The only mixing ratio investigated in the present study was $20 \mathrm{wt} \%$. The addition of less of the methacrylate monomers may change the fluidity properties of other urethane oligomers. Additionally, ESLM must keep their shape until irradiated with visible light. Further measurements such as those assessing thixotropic properties should also be performed.

Elasticity is another important property of soft lining materials. In a previous study ${ }^{10}$, dynamic measurements demonstrated that the storage modulus of polyethylmethacrylate, which is heatcured by the powder-liquid method, was $2.31 \mathrm{GPa}$ and that of n-polybutylmethacrylate was $0.83 \mathrm{GPa}$ at $37^{\circ} \mathrm{C}$. These values are greater than the modulus of polymerized urethane, although the measuring methods differed. In the present study, the compressive modulus did not increase after the addition of methacrylate monomers $(p>005)$, and this may be useful for maintaining softness. The linear polymers made from EMA or BMA should be dispersed in the polymerized and cross-linked urethane structures. The principal chain structure of the urethane primarily controlled the flexibility of the test specimens. Its structure can be examined by measuring the molecular weight distribution by a technique such as HPLC.
Elastic moduli of 0.4-0.5 $\mathrm{MPa}$ for acrylic soft lining materials and 0.5-2.0 $\mathrm{MPa}$ for silicone rubber have been reported ${ }^{11}$. These are lower than the elastic moduli of the materials in the present investigation, except for U34 (0.3 $\mathrm{MPa})$. In a previous study $^{12)}$, the modulus of oral soft tissue ranged from 0.7 to $4.4 \mathrm{MPa}$. Future investigations, including questionnaires for denture users, are needed to clarify whether the elasticity of soft lining materials should be lower or higher than that of oral soft tissue.

There were significant differences in the viscosity with the addition of EMA and that with the addition of BMA in U10, U16, U34, and U80 $(\mathrm{p}<0.01)$; however, in some cases, the change in viscosity was small compared with the viscosity of the urethane oligomer without methacrylate monomers (Fig. 1). In fact, when the results for U22 and S98 were excluded from the analysis, there was no statistically significant difference in viscosity with the addition of the two methacrylate monomers $(p>0.05)$. These results show that the diluents for urethane oligomers were affected by both methacrylate monomers and that the selection of a diluent should include consideration of other factors such as hardness.

Surface hardness also affects oral sensitivity in chewing. Softer lining materials would fit better with the oral mucosa, but extremely soft materials would likely make it difficult to chew some foods and to fix the denture in the desired position. The Shore A hardnesses of polymers of the six ESMLs without methacrylate monomers ranged from 0.9 to 87.2. According to a previous study ${ }^{11)}$, the Shore A hardness of acrylic and silicone type soft lining materials ranged from 2.0 to 39.5 , and the highest frequency of variation in the hardness of oral soft tissue was 5-10, measured using a trial hardness tester ${ }^{13)}$. The hardness $(9.3,6.0$, and 11.9) measured using a same trial hardness tester increases compared with that $(2.0,2.7$, and 3.7) of the Shore A hardness tester ${ }^{9}$. When the hardness of oral soft tissue is converted into the Shore A hardness, it will be a little small. If the hardness value were to be similar to that of oral soft tissue, U34 without methacrylate monomers (hardness, 0.9) would be appropriate. The hardness values for U16 with BMA and S98 with EMA were 0.88 and 1.14 times that of urethane oligomer without methacrylate monomers, and the values for U22 with EMA or BMA were 0.83 or 0.72 times that of urethane oligomer without methacrylate monomers. The addition of less of the methacrylate monomers to the urethane oligomers may reduce these changes in hardness. If more effective method in controlling the hardness is needed, the mixing of two urethane oligomers should be employed ${ }^{14}$.

Waters and Jagger ${ }^{15}$ measured the tensile 
strength of commercially available and experimental silicone soft lining materials, reporting values of 2.12 and $5.20 \mathrm{MPa}$, respectively. In that report, testing speed of $500 \mathrm{~mm} / \mathrm{min}$ is employed, and so the tensile strength may be a little larger than that of $254 \mathrm{~mm} /$ min. However, the tensile strength needed for dental use is unclear. The tensile strengths of U16, U80, and S98 without methacrylate monomers were 5.2, 14.7 , and $7.7 \mathrm{MPa}$, respectively. In the present investigation, only U80 and S98 with EMA showed increased tensile strength after monomer addition. Thus, the urethane polymer matrix primarily controls the tensile strength.

Acrylic soft resilient materials are used for tissue conditioners, functional impression materials, and temporary lining materials. The elution of ethyl alcohol from soft lining materials can cause loss of softness in the materials, deterioration in surface conditions over time, and patient complaints because of the bitter taste of the alcohol ${ }^{16,17)}$. Thus, alcoholfree and other plasticizer-free soft lining materials are desirable for denture users. Silicone type soft lining materials, which are alcohol-free, are typically used for relining materials, but these materials require adhesives to bond with an acrylate denture base. The urethane polymer used in the present investigation was alcohol-free, as was the elastomer. However, no primer or finishing material was necessary for bonding with acrylic denture base materials. We previously reported that the adhesive strength between ESLMs and acrylic denture base materials was $3.8 \mathrm{MPa}$ at 1 day after polymerization $^{7)}$.

Generally, urethane acrylate is made by a first reaction of polyols and organic isocyanates, followed by a second reaction of acrylate monomers. In the design process, urethane polymers made from urethane oligomers become softer as the number of functional groups decreases ${ }^{18}$. Urethane oligomers with two functional groups were chosen for the six ESLMs used in this investigation. In clinical use, some urethane polymers are also used for catheters and ventricular assist systems ${ }^{19)}$, and urethane dimethacrylate monomer, which is hard after polymerization, is used for some dental composite resins. However, cytotoxicity is also a critical factor in dental use, and biogenic safety must be confirmed for these individual materials. We tested the six urethane polymers in the present study by using the MTT assay to assess the viability of HeLa and Ca9-22 cells. Some urethane polymers for ESLM (S98 in this investigation) have been reported to have low cytotoxicity ${ }^{20)}$.

In conclusion, the addition of ethyl- or butylmethacrylate monomers to urethane oligomers effectively decreased the viscosity of ESLM, without affecting the mechanical properties.

\section{ACKNOWLEDGEMENTS}

This work was partially supported by a grant from the R\&D matching fund of NEDO and by a Grant-inAid for Scientific Research (No. 17592031) from the Japan Society for the Promotion of Science.

\section{REFERENCES}

1) Mutluay MM, Ruyter IE. Evaluation of bond strength of soft relining materials to denture base polymers. Dent Mater 2007; 23: 1373-1381.

2) Aloul RK, Shen C. The influence of plasticizer loss on the viscoelasticity of temporary soft liners. J Prosthodont 2002; 11: 254-262.

3) Fujii K, Arikawa H, Kanie T, Shinohara N, Inoue K. Effect of photo-irradiation on hardness of soft lining materials for denture base. J Oral Rehabil 2002; 29: 744-748

4) Sertgoz A, Kulak Y, Gedik H, Taskonak B. The effect of thermocycling on peel strength of six soft lining materials. J Oral Rehabil 2002; 29: 583-587.

5) Kulak-Ozkan Y, Sertgoz A, Gedik H. Effect of thermocycling on tensile bond strength of six silicone-based, resilient denture liners. J Prosthet Dent 2003; 89: 303-310.

6) Kanie T, Arikawa H, Fujii K, Ban S. Light-curing reinforcement for denture base resin using a glass fiber cloth pre-impregnation with various urethane oligomers. Dent Mater J 2004; 23: 291-296.

7) Kanie T, Kadokawa A, Arikawa H, Fujii K, Ban S. Mechanical properties of an experimental soft lining material based on urethane oligomer. Dent Mater J 2005; 24: 433-439.

8) Japanese Standards Association. JIS Handbook 19 Rubber, Japanese Standards Association, Tokyo, 1993, pp107-112.

9) Fujii K, Minami H, Arikawa H, Kanie T, Ban S. Mechanical properties and bond strength of siliconebased resilient denture liners. Dent Mater J 2005; 24: 667-675.

10) Kanie T, Seki H, Masuda A, Imaizumi A, Fujii K, Inoue K. Viscoelastic properties and impact strength of denture base resins added of alkylmethacrylates. J J Dent Mater 1997; 16: 83-89.

11) Inoue $\mathrm{K}$, Itonaga $\mathrm{A}$, Tsuruda $\mathrm{H}$, Terao $\mathrm{T}$, Yamashita H, Tsukada G, Oku J, Arikawa H, Kanie T, Fujii K. Hardness and elastic modulus in compression of denture base soft lining materials determined by a modified experimental hardness tester. J J Dent Mater 1993; 12: 346-351.

12) Inoue $\mathrm{K}$, Arikawa H, Fujii $\mathrm{K}$, Shinohara N, Kawahata N. Viscoelastic properties of oral soft tissue 1. A method of determining elastic modulus of oral soft tissue. Dent Mater J 1985; 4: 47-53.

13) Inoue $\mathrm{K}$, Itonaga $\mathrm{A}$, Tsuruda $\mathrm{H}$, Arikawa $\mathrm{H}$, Kanie T, Fujii K, Hamano T, Kishita C, Nagaoka E. Comparison of the hardness of tissue conditioners and oral soft tissue measured by a modified hardness tester. Dentistry in Japan 1993; 30: 110-114.

14) Kanie T, Kadokawa A, Arikawa H, Fujii K, Ban S. Mechanical properties of a soft liner made of 
methacrylate monomers and urethane oligomers. Proceedings of the IDMC 2007; 245.

15) Waters MG, Jagger RG. Mechanical properties of an experimental denture soft lining material. J Dent 1999; 27: 197-202.

16) Murata H, Narasaki Y, Hamada T, McCabe JF. An alcohol-free tissue conditioner-A laboratory evaluation. J Dent 2006; 34: 307-315.

17) Hashimoto Y, Tanaka J, Suzuki K, Nakamura M. Cytocompatibility of a tissue conditioner containing vinyl monomer as a plasticizer. Dnet Mater J 2007; 26: 785-791.
18) Editing section of CMC Publishing Co. Market \& prospect of UV/EB radiation curing material and product. CMC Publishing Co., Tokyo, 2007, pp 4546.

19) Satoh M. Stabilization and deterioration measure of the polyurethane and new reforming technology fitted with each purposes. Technical Information Institute Co., Tokyo, 2004, pp 404-412.

20) Tomita K, Tabuti S, Takenaka A, Tokuda M, Torii M, Kanie T, Ban S. Cytotoxicity of a soft liner made of urethane polymers. Proceedings of the IDMC $2007 ; 359$. 